\title{
Control system of temperature of locomotives traction frequency converters
}

\author{
Andrey Kosmodamianskiy ${ }^{1 *}$, Alexander Pugachev ${ }^{2}$, and Nikolay Strekalov ${ }^{1}$ \\ ${ }^{1}$ Russian University of Transport, 127994 Moscow, Russia \\ ${ }^{2}$ Bryansk State Technical University, 241035 Bryansk, Russia
}

\begin{abstract}
The features of the control systems of temperature of the traction frequency converters consisted of rectifier, capacitor and voltage source inverter for traction rolling stock are discussed. The induction motor is considered as a load for traction frequency converter. The dependence of the number of thermal cycles from semiconductor junction temperature fluctuations before the failure of the semiconductor device are shown. The topology and operation principle of automatic temperature control system of voltage source inverter semiconductor devices of traction frequency converter are developed and described. The system is based on air forced cooling with the use of fan or blower as an executive regulation device. The main feature of the proposed system is the additional reference of switching frequency that allows to reduce the semiconductor temperature fluctuations. The elements of switching frequency control loop are chosen and evaluated, the recommendations on practical implementations are given. Simulation of automatic temperature control system in Matlab with both references of semiconductor junction temperature and its fluctuation was carried out with all essential nonlinearities of induction motors and semiconductor devices taken into account. Results of simulation are included and discussed.
\end{abstract}

\section{Introduction}

Survey of various researches and publications $[1,2,3]$ shows that the main malfunctions and damages of power semiconductor devices at long current loads are caused by processes of thermomechanical aging of solders, defects in contacts between cooling radiators and power semiconductor devices, damages of semiconductor structures caused by significant temperature changes during unregulated cooling. The thermal state of power semiconductor devices and traction semiconductor converter units and the nature of its change are directly related to their reliability indicators such as failure rate and cycling resistance [4]. Converter temperature also affects operation modes of electric drive control system [5]. Thus, temperature stabilization is necessary to increase the reliability of traction semiconductor converters and their cooling systems, reduce the consumption of electricity or fuel for cooling [6].

${ }^{*}$ Corresponding author: askosm@mail.ru 
All forced cooling systems have to satisfy the basic requirements such as ensuring maximum uniformity of coolant supply to the cooling surface of the power semiconductor module, minimization of power consumption for coolant circulation, provision of possibility of converter cooling system assembly and maintenance, minimization of costs associated with the manufacture and purchase of components, ensuring the tightness of the liquid circuit in the area of the installation of the power module and other electrical equipment of the converter (for liquid cooling).

In Russia, for a long time, traction static converters of locomotives were carried out with a forced air cooling system. There is no such unambiguity abroad. So, for example, the traction converter of diesel locomotives of the Eurorunner ER20, manufactured by Siemens AG, contains a liquid cooling system. Bombardier Transportation TRAXX converters have the same cooling system. On the other hand, diesel locomotives of the Evolution (USA) have traction converters with a forced air cooling system. Analysis of works $[7,8]$ shows that the use of an air forced cooling system is preferable up to $550 \mathrm{~kW}$ capacities with single transistors.

So, the investigation and development of techniques of temperature control of locomotives traction frequency converters are still relevant and important. The authors of this article lay down the control system of temperature provided control both the average temperature of traction converter semiconductors and its fluctuations.

\section{Automatic temperature control system of semiconductors}

The use of the common control systems of temperature of power semiconductor devices allows maintaining a controlled temperature in the range of permissible values due to the use of additional feedback of load current, temperature of external cooling air and air supply by the fan. At the same time, during operation, temperature fluctuations inevitably occur due to high-frequency switching losses, which negatively affects the reliability of semiconductors and reduces their service life. In order to expand the range of temperature control and reduce the amplitude of temperature changes of semiconductors, the combined automatic temperature control system of semiconductor devices is developed. The system has two references: the first one is the semiconductor junction temperature, which delivered by the supply of cooling air, and the second reference introduced by the authors is the semiconductor junction temperature fluctuations, which delivered by the switching frequency of semiconductors. Some details about various ways to cool semiconductor devices are considered in $[9,10,11]$.

\subsection{Influence of temperature fluctuation on the service life of semiconductors}

The dependence of the number of thermal cycles from semiconductor junction temperature fluctuations before the failure of the semiconductor device on a logarithmic scale is shown in Fig. 1 (in Fig. 1 and below the $\theta_{j, a v}$ denotes the average temperature of semiconductor junction) [12]. Obviously, it is not enough to monitor only the average or maximum temperature value for reliable operation of the voltage source inverter, even with a low average temperature value, its fluctuations can significantly reduce the operating time to failure due to fatigue damage caused by constant dynamic thermal loads.

In this regard, the task of limiting not only the temperature value but also its fluctuations becomes relevant. In principle, temperature fluctuations can be reduced in two ways: by using a combined automatic temperature control system, i.e. acting initially on the temperature of the cooling air or liquid and cooler, or by applying modulation parameter control (switching frequency or modulation coefficient), i.e. initially affecting switching losses that cause heating of the semiconductor junction itself. Since, due to the design 
features and physical processes of heat transfer, the junction has the highest temperature in any semiconductor, and it is its temperature that affects the properties of the $p-n$ junction, the authors propose a technique for controlling temperature fluctuations based on a change in modulation parameters.

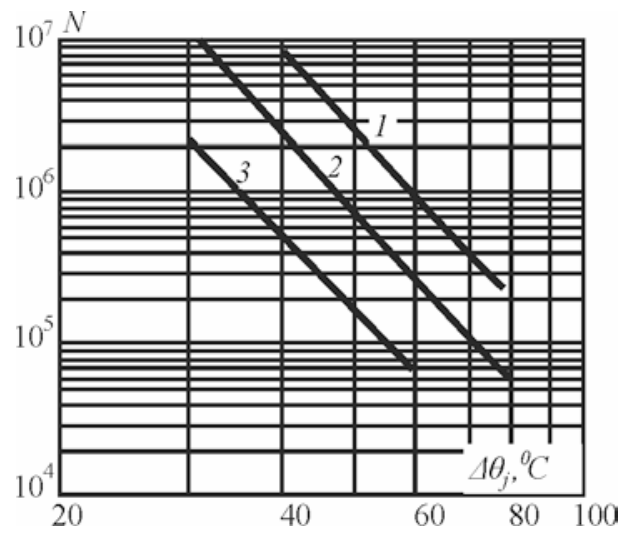

Fig. 1. Dependence of limit number of thermal cycles $N$ from semiconductor junction temperature fluctuations $\Delta \theta_{j}\left(1-\theta_{j, a v}=60^{\circ} \mathrm{C}, 2-\theta_{j, a v}=80^{\circ} \mathrm{C}, 3-\theta_{j, a v}=100^{\circ} \mathrm{C}\right)$.

Obviously, this approach affects processes not only in a vokltage source inverter but also in its load that is an induction motor stator winding. The analysis of electromechanical and control processes makes it possible to conclude that the most favorable parameter suitable for changing in a wide range of operating modes of an induction motor is the switching frequency of power switches.

\subsection{The system topology}

The combined automatic temperature control system of the semiconductor junction and its fluctuations is shown in Fig. 2. The generally accepted on the locomotives cooling system is encircled by rectangular. Investigation of this system was carried out in [13]. Also, in [14] developed the electric drive of cooling system consisting of induction motor and frequency converter with control system provided the minimum current stator and minimum power losses in induction motor of cooling system.

The principle of the system is follows. If temperature fluctuations $\Delta \theta_{j}$ are less than the reference $\Delta \theta_{j, r e f}$, then the switch $S$ is connected to the upper state and the voltage source inverter $V S I$ operates at a constant switching frequency $f_{k}$ determined by the reference $f_{k, r e f}$. If the temperature fluctuations $\Delta \theta_{j, \text { ref }}$ are greater than $\Delta \theta_{j, r e f}$, then he switch $S$ is connected to the lower state, thereby setting on the switching frequency control loop. The most accurate version of temperature control is by means of temperature sensor, but for a number of practical reasons it is difficult to install the sensor; in this case, indirect determination of temperature by the expressions determined in [15] is possible.

To find the value of temperature fluctuations $\Delta \theta_{j}$, it is necessary to compare two of its extreme values, which can be performed using a first-order filter. In practical implementation, a digital implementation of the filter is advisable.

A PID controller is used as a temperature fluctuation regulator in this work, an alternative to which can be proposed the use of a multi-position relay regulator. 


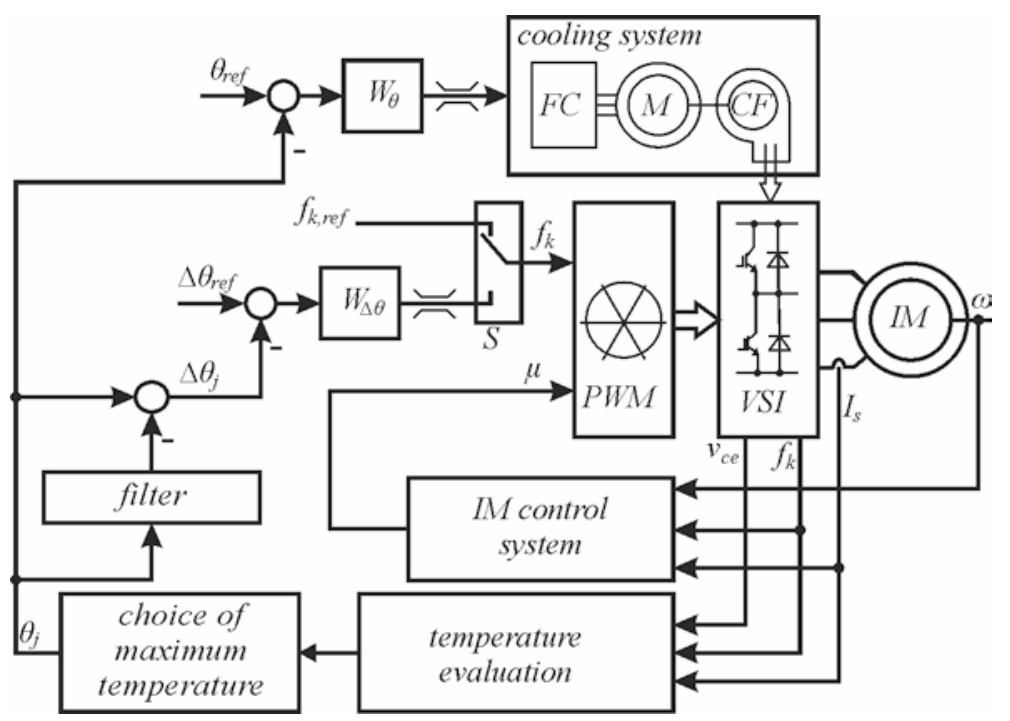

Fig. 2. Topology of the system ( $F C$ denotes the frequency converter, $M$ does the motor of cooling fan $C F, P W M$ does the algorithms of pulse wide modulation, VSI does the voltage source invertor of the traction frequency converter, $I M$ does the traction induction motor, $\theta_{\text {ref }}$ does the semiconductor temperature reference, $f_{k, \text { ref }}$ does the semiconductor switching frequency reference, $\mu$ does the $P W M$ modulation parameters, $\omega$ does the $I M$ speed, $v_{c e}$ does collector-emitter voltage of IGBT, the $W_{\theta}$ and $W_{\Delta \theta}$ do the controllers of respective variables)

Limitation of output values of switching frequency PID controller must be performed by maximum and minimum values.

The maximum value of switching frequency is limited, first of all, by the time when the semiconductor is turned on $t_{\text {on }}$ and off $t_{\text {off: }}$ :

$$
f_{k, \max } \leq 1 /\left[\pi\left(t_{o n}+t_{o f f}\right)\right] .
$$

In addition, the maximum frequency is also limited by the maximum power consumption $P_{\max }$ during the switched-on state $\Delta t$ during the switching period $T_{k}$ :

$$
\left.f_{k, \max } \leq P_{\max } /\left[E_{\text {on }}+E_{\text {off }}+I_{c}{ }^{2} R \Delta t\right)\right] \quad,
$$

where $E_{\text {on }}$ and $E_{\text {off }}$ denote the turn on and turn off energy of the semiconductor, $I_{c}$ does the collector current, $R$ does the resistance of semiconductor during the switched-on state.

The minimum switching frequency has to meet to the requirement of satisfactory harmonic current composition of the stator of the induction motor, which, in turn, affects the heating of the stator and rotor windings and the value of torque pulsations. Thus, if the maximum value $f_{k}$ is a function of the semiconductors themselves and depends little on the type of load and its characteristics, then the minimum value $f_{k}$ depends primarily on the properties of the load. For the traction frequency converter, the minimum switching frequency value is determined by the thermal state of the traction motor and its implementation of the traction task.

\section{Results of simulation and discussion}

Simulation of the proposed system were carried out in Matlab software. The mathematical and algorithmic description of cooling system shown in the top of the Fig. 2 
are taken from [13]. The mathematical model of thermal processes in voltage source inverter of traction frequency converter including temperature and its fluctuation dependence on voltage source inverter switching frequency are given in [15]. The topology, operation principles and the main equations of auxiliary electric drive control system of cooling fan and the traction electric drive control system are described in [14] and [16] respectively. All these publications are authors' previous investigations.

Results of implementation of combined automatic temperature control system obtained by simulation are shown in Fig. 3. Obviously, the synthesized system delivers the ability to control the switching frequency $f_{k}$, and, as a result, the temperature of the semiconductor. Simulation was carried out for the $360 \mathrm{~kW}$ induction motor electric drive. The results of the simulation also show that the change of $f_{k}$ leads to a change of the average temperature $\theta_{j, a v}$, a decrease of $f_{k}$ causes a simultaneous decrease of $\Delta \theta_{j}$ and $\theta_{j, a v}$.

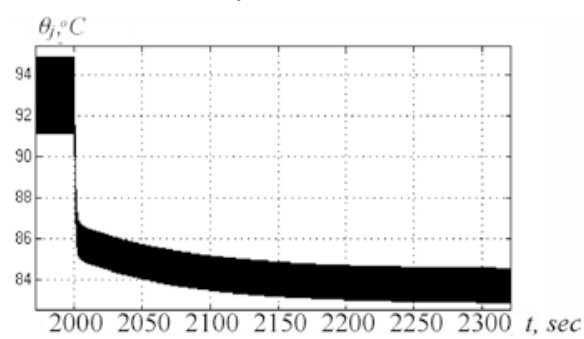

a)

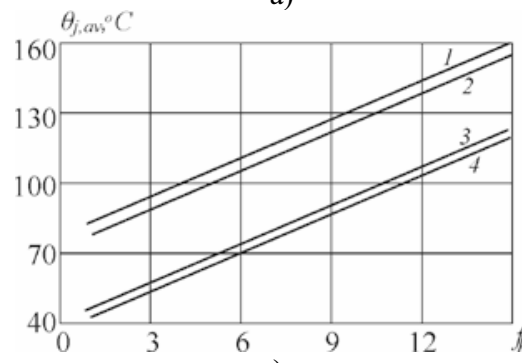

c)

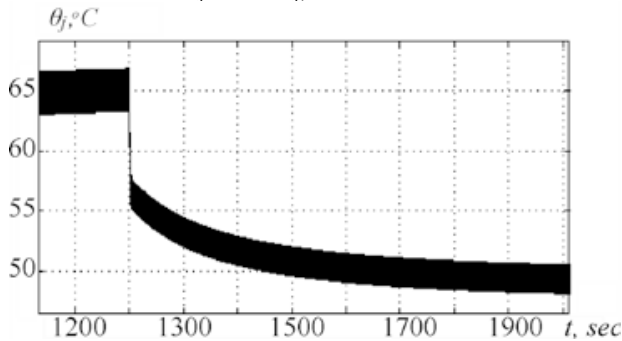

b)

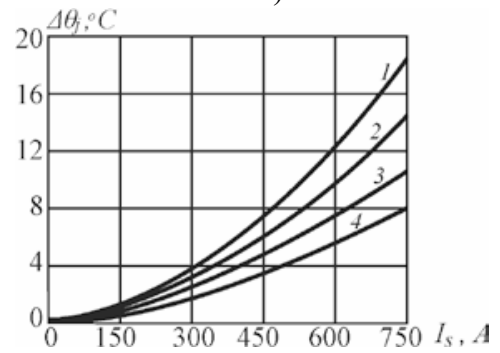

d)

Fig. 3. Results of simulation: a) temperature of voltage source inverter IGBT junction vs. time ( $f_{k}$ changes from $2 \mathrm{kHz}$ to $1 \mathrm{kHz}$ at the $t=2000 \mathrm{sec}$ ), b) temperature of voltage source inverter IGBT junction vs. time (air supply by cooling fan changes from 0 to $0.01 \mathrm{~m}^{3} / \mathrm{sec}$ at the $t=1250 \mathrm{sec}$ ), c) average temperature $\theta_{j, a v}$ vs. switching frequency $\left(1-\theta_{j, a v}\right.$ of voltage source inverter IGBT junction, $2-\theta_{j, a v}$ of rectifier diode at the free convection, 3 and $4-$ the same at the air forced convection), d) temperature fluctuations of voltage source inverter IGBT junction vs. stator current $\left(1-f_{k}=20 \mathrm{kHz}\right.$, $\left.2-f_{k}=15 \mathrm{kHz}, 3-f_{k}=10 \mathrm{kHz}, 4-f_{k}=5 \mathrm{kHz}\right)$

As a result of the simulation, it was also found that increasing the power of the induction motor and, accordingly, semiconductor devices shifts the range of recommended switching frequencies towards smaller values. For example, for the $14 \mathrm{~kW}$ induction motor it is calculated that $f_{k}=5 \ldots 36 \mathrm{kHz}$, for a motor with a power of $360 \mathrm{~kW}-f_{k}=1 \ldots \ldots 8 \mathrm{kHz}$.

The considered approaches to controlling the average temperature and its fluctuations in semiconductor devices have to be separated in practical application. So, maintaining temperature within the limits is the task of the first loop including cooling system with fans or pumps, while the task of the second loop with switching frequency reference is to reduce temperature fluctuations. The usefulness of the whole control system increases when the operation of the semiconductor cooling system is not directly related to their temperature, that is in the absence of feedback and control over the deviation of the controlled value which occurs on most of the modern traction rolling stock. 


\section{Conclusion}

This article presents investigation dedicated to enhancements of cooling system of locomotive traction frequency converter. This is reached by introduction of additional reference to the automatic temperature control system. So, the proposed system has two references: the temperature of semiconductor junction (conventional reference) and temperature fluctuations. The control of this variables is obtained by means of changing of air supply and frequency switching of semiconductor devices. The monitoring of temperature and its fluctuations are provided by implementation of mathematical model of thermal processes in the semiconductor devices. Results of simulation in state and transient modes show the adequacy of developed system in terms of thermal behavior of both rectifier diodes and voltage source inverter IGBT.

\section{References}

1. O.V. Thorsen, M. Dalva, A survey of the reliability with an analasis of faults on variable frequency drives with in industry, EPE'95, Spain, pp. 1033 - 1038 (1995)

2. P. Lezana, J. Poy, T.A. Meynard, J. Rodriguez, S. Ceballos, F. Richardean, Survey on fault operation on multilevel inverters, IEEE Transactions on Industrial Electronics, 57, pp. 2207 -2218 (2010)

3. H. Wang, M. Liserre, F. Blaabjerg, Toward reliable power electronics - challenges, design tools and opportunities, IEEE Ind. Electr. Magazine, 7, pp. 17-26 (2013)

4. V. Blasko [et al.] On Line Thermal model and Thermal Management Strategy of a Three Phase Voltage Source Inverter, Industry Applications Conference, pp. 1423 1431 (1999)

5. V. Krishnan, Electric Motor Drives: modeling, analysis and control. Virginia Tech, Blacksburg, VA (2001)

6. Yu.M. In'kov, A.S. Kosmodamiansky, A.V. Lukin, A.A. Pugachev, N.N. Strekalov, A System for Controlling the Thermal Behavior of Voltage Source Inverters, Russian Electrical Engineering, 91, pp. 537 - 540 (2020)

7. D.A. Murdock, J.E. Ramos Torres, J.J. Connors, R.D. Lorenz, Active thermal control of power electronics module, IEEE Transactions on Industry Applications, 42, pp. 552 - 558 (2006)

8. P. Bachman, R. Haiduk, The effect of forced air cooling on heat sink thermal ratings, white paper

9. L. Noelle, Cooling methods for industrial electronics, Fischer Electronic (2002)

10. J.W. Leong, Y.L. Lee, Study on the optimization of IGBT thermal management for PTC heater, Journal of Engineering Scienceand Technology, 10, pp. 1575 - 1588, (2015)

11. A. S. Bahman, K. Ma, F. Blaabjerg, Thermal impedance model of high power IGBT modules considering heat coupling effects, Power Electronics and Application Conference and Exposition (2014)

12. W. Junke, Z. Luowei, S. Pengju, D. Xiong, Control of IGBT junction temperature in small-scale wind power converter, International Power Electronics and Application Conference and Exposition, pp. 41 - 48 (2014) 
13. A.A. Pugachev, N.N. Strekalov, Temperature control of power semiconductor devices in traction applications, IOP Conf. Series: Materials Science and Engineering ,177 (2017)

14. A. Pugachev, A. Kosmodamianskiy, Induction motor scalar control system with power losses minimization, Proceedings of 2019 International Conference on Industrial Engineering, Applications and Manufacturing (2019)

15. Yu.M. In'kov, A.S. Kosmodamianskii, L.M. Klyachko, A.A. Pugachev, Simulation of the thermal state of self-excited voltage source inverters, Russian Electrical Engineering, 90, pp. 620 - 624 (2019)

16. A.S. Kosmodamianskii, L.M. Klyachko, V.I. Vorobiev, A.A. Pugachev, Control system of a tractive drive with temperature control of thermally loaded elements, Russian Electrical Engineering, 85, pp. 513 - 518 (2014) 